\title{
Decision-Making by Emergency Medicine Personnel in Prehospital Treatment of Patients Receiving Palliative Care: A Questionnaire, Comparative Cohort Study
}

\section{Thidathit Prachanukool Chaiyaporn Yuksen (D) Sirada Jintanavasan Chetsadakon Jenpanitpong (D) Sorawich Watcharakitpaisan (ID Parama Kaninworapan Konwachira Maijan}

Department of Emergency Medicine, Faculty of Medicine Ramathibodi Hospital, Mahidol University, Bangkok, Thailand
Correspondence: Chaiyaporn Yuksen Department of Emergency Medicine, Faculty of Medicine, Ramathibodi Hospital, Mahidol University, Bangkok, Thailand

Tel +668-9472-69l

Fax +66-220I-2404

Email chaiyapool0634@hotmail.com
Objective: Palliative care is an approach to improve quality of life in patients with lifelimiting diseases. The sudden nature of such conditions involves emergency providers as the first responders, who have roles in delivering appropriate care to meet patients' needs. In this study, we evaluated whether previous experience in palliative care among paramedic students could affect their decision-making skills in prehospital work.

Methods: This questionnaire-based prospective cross-sectional study was conducted from October 2019 to November 2020. We compared two groups of paramedic students in a tertiary hospital in Bangkok, Thailand. The class of 2019 did not attend palliative care courses and the class of 2020 completed a 2-week course regarding in-hospital palliative care services. Questionnaires including rating scales and checklists and involving cases with and without malignancy were completed via a web-based data collection form. The reliability of the questionnaire was tested. Decision-making skills were categorized into seven domains comprising life-sustaining treatment, withholding or withdrawing life-sustaining treatment, advance care planning, self-autonomy, decision-making capacity and surrogate decisionmakers, prehospital dyspnea management, and communication skills.

Results: Among 57 paramedics, 52 (91\%) completed the questionnaire. There was no significant difference in decision-making between the two groups in all seven domains ( $p>0.050)$. Overall, participants more often recognized patients who were eligible for palliative care and made more decisions to withhold or withdraw life-sustaining treatment when patients had advanced malignancy than in cases of non-malignancy ( $100 \%$ and $84.6 \%$ respectively, $\mathrm{p}=0.006)$.

Conclusion: Our findings showed that the decision-making process for patients regarding prehospital palliative care was not significantly different between two groups of emergency personnel with and without in-hospital palliative care experience.

Keywords: emergency medical service, emergency personnel, palliative care, paramedics, prehospital care

\section{Introduction}

Palliative care is defined by the World Health Organization as an approach to improve quality of life in patients with life-threatening or life-limiting conditions or diseases. ${ }^{1}$ The goal of palliative care is to provide the best possible quality of life for such patients and their families. ${ }^{2}$ Palliative care is not focused only on relieving distressing symptoms but also on psychological care, social care, spiritual care, and ethical and legal aspects of care, ensuring that patients can die with dignity. ${ }^{3-6}$ 
The most common symptoms experienced by patients receiving palliative care include pain, dyspnea, terminal restlessness, and altered mental status. ${ }^{7}$ As these symptoms are usually sudden, emergency medical service (EMS) officers are often the first health care staff to deliver appropriate and timely treatment. ${ }^{5}$ As leaders of the advanced life support team, advanced emergency workers play a crucial role in prehospital care services. ${ }^{1,8}$ These professionals may need to carry out life-saving procedures and make important decisions.

To better understand emergency care practices from the perspective of palliative care, the Education in Palliative Care and End of Life Care in Emergency Medicine (EPECEM) project was established. ${ }^{9}$ This includes a comprehensive curriculum in palliative care for emergency staff and provides personnel with necessary skills and knowledge to care for patients they encounter. However, this scope of practice remains a new area of prehospital training in Thailand. Institutes that provide paramedic training in advanced life support leadership on EMS teams have been established for less than 10 years. It is challenging for emergency operators to achieve palliative care goals without consensus regarding the curriculum for prehospital palliative care. ${ }^{4,7}$ As a result, limited training makes emergency workers feel unprepared to offer this kind of treatment. ${ }^{1,7,10,11}$

The Department of Emergency Medicine of Ramathibodi Hospital established a 4-year Bachelor of Science program in paramedic training in 2014. The class of 2019 did not attend palliative care courses. Students in the class of 2020 completed a 2-week palliative care course during their third year of training in RAER 313 (Emergency Medical Field Work 1) subjects. The course comprised three lectures on basic palliative care, communication in end-of-life care, and the role of prehospital workers in palliative care. Students attended palliative care clinics and in-hospital palliative care services but did not have formal training with out-of-hospital cases. We conducted this study to evaluate whether previous experience in palliative care among paramedic students affects their decision-making skills in EMS work.

\section{Methods}

\section{Study Design}

This comparative cohort study was conducted from October 2019 to November 2020 in the Department of Emergency Medicine, Faculty of Medicine Ramathibodi
Hospital, which is the tertiary care hospital of the University.

\section{Study Population}

Participants were paramedics who graduated in the first two generations of the program (classes of 2019 and 2020). The first group did not complete palliative care course, but the second group completed a 2-week course in palliative care practice. Participants had 6 months of working experience before joining this study.

\section{Questionnaire}

The questionnaire used in this study was developed from an attending staff of the Department of Emergency Medicine, who are emergency physicians and also certified of advanced palliative care in Thailand. The seven domains of knowledge are based on the basis of the EPECEM project curriculum, which consists of 17 modules. ${ }^{8,12}$ We recategorized these modules into seven domains corresponding with Thai EMS services and practices. The questionnaire evaluated decision-making regarding lifesustaining treatment, withholding or withdrawing lifesustaining treatment, advance care planning and living wills, self-autonomy, decision-making capacity and surrogate decision-makers, prehospital dyspnea management, and communication skills (Appendix 1 and 2).

The questionnaire consisted of two scenario-based cases involving patients with and without malignancy. We assessed six of seven domains in each case. In cases without malignancy, we did not evaluate decision-making regarding a living will and advanced directive. In the case of malignancy, we did not evaluate dyspnea management skills because the patient presented with cardiac arrest. Each case included rating scales from 1 to 10 or checklists from which to choose the five most appropriate options.

For rating scales, participants were scored according to the selected scale. Participants were considered to have decision-making skills if they scored at least 5 out of 10 points. For checklists in dyspnea control and communication skills, participants were scored by comparing their answers to the five most appropriate treatment options and an ask-tell-ask communication model. ${ }^{13}$

We conducted a pilot study to measure the reliability of the questionnaire by recruiting 14 paramedics who had experience and worked in similar settings as our participant population. We used Cronbach's $\alpha$ coefficient to evaluate the internal consistency and reliability of the 
test. The Cronbach's $\alpha$ coefficient was 0.702 , meaning the reliability of this research tool was within an acceptable range. ${ }^{14}$

The questionnaire was administered individually to each participant via a web-based data collection form. Informed consent was obtained before questionnaire completion by clicking an "Accept" button. Participants who did not provide informed consent were excluded from the study.

This research was approved by the Committee for Research, Faculty of Medicine Ramathibodi Hospital, Mahidol University (COA. MURA2019/1203) and is registered in the Thai Clinical Trials Registry (TCTR20200526015).

\section{Statistical Analysis}

Data are presented as number with percentage for categorical data and mean with standard deviation or median with interquartile range for numerical data, as appropriate. The chi-square or Fisher's exact test was used for categorical variables, as appropriate. A p-value less than 0.05 was considered significant. Stata version 16.1 was used for statistical analysis (StataCorp LLC., College Station, TX, USA).

\section{Results}

\section{Baseline Characteristics}

During the 2-year study period, a total of 57 questionnaires were distributed. By the end of the study, 25 of 26 (96\%) paramedics from the class of 2019 and 27 of 31 (87\%) paramedics from the class of 2020 had completed the questionnaire (Figure 1).

The mean age of participants was 26 years, and 29 (56\%) participants were men. Twenty-four (46\%) participants were currently working in teaching hospitals; 23 (44\%) had previous jobs before becoming a paramedic; and $16(31 \%)$ had experience in caring for patients receiving palliative care. All of them work for EMS in different sizes of hospitals, with different abilities and

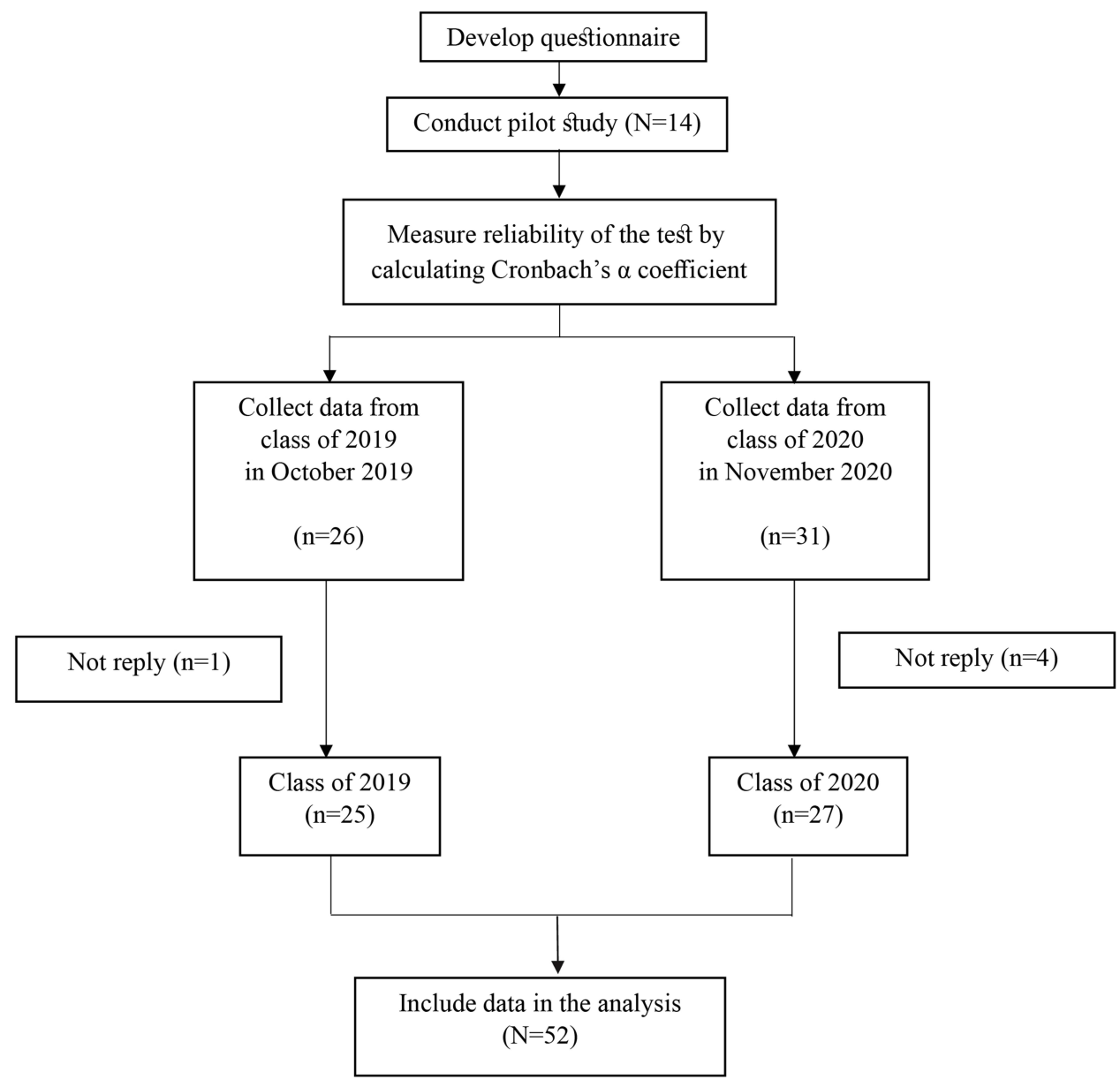

Figure I Study flow chart. 
responsibilities. The EMS system in Thailand is hospitalbased and each hospital has its own EMS unit that cooperates with the national EMS center. Overall, 96 of 104 (92.3\%) participants could recognize patients who were eligible for palliative care (Table 1). Each participant was tested twice for the domain "Ability to recognize patients eligible for palliative care", once with patients who had malignancy and once with patients who did not have malignancy; therefore, the number of samples in that domain was double the number in other domains.

\section{Decision-Making}

There was no significant difference in decision-making between the two groups in all seven domains $(\mathrm{p}>0.050)$ for patients both with and without malignancy (Table 2). Overall, recognition of patients who were eligible to receive palliative care was significantly different for the two types of patients $(p=0.006)$. The data also showed that overall decisions to withhold or withdraw life-sustaining treatment were significantly different for patients with and without malignancy $(\mathrm{p}=0.006)$. The results are given in Table 3 .

\section{Discussion}

In general, emergency providers' decisions are influenced by six main factors (1) early integration of an outpatient palliative care system, (2) patients' awareness of their disease trajectory, (3) emergency medical documents, (4) law and health regulations, (5) training systems, and (6) the EMS system. ${ }^{15}$

Early integration of an outpatient palliative care system is believed to have the greatest impact on decision-making. This should begin in an earlier stage while the patient is still in an ambulatory setting. ${ }^{16}$ Recent studies have shown that early participation in an outpatient palliative care clinic influences the quality of end-of-life care ${ }^{17}$ and is associated with a reduction in the symptom burden and emergency department visits. ${ }^{18}$ We encourage hospitals to establish and reinforce such collaboration to prevent delays in palliative care consultation and other subsequent processes.

The disease trajectory and patient's awareness of the course of disease also influence providers' decisions. ${ }^{19}$ Previous studies have shown that the dying process has an effect on the time of initiating palliative care consultation, intensity of care, and length of stay in the hospital. ${ }^{20}$ Moreover, if patients and family are aware of their course of disease, they can more easily guide the prognosis, expectations, and goals of treatment. ${ }^{2}$ An opinion from participant was quoted

Patients and their families were unaware of the disease's progression. Perhaps no one had informed them

Table I Baseline Characteristics Among Participants, by Class

\begin{tabular}{|c|c|c|c|c|}
\hline Baseline Characteristic & All $\mathbf{N}=52$ & $\begin{array}{l}\text { Class of } 2019 \\
\qquad N=25\end{array}$ & $\begin{array}{c}\text { Class of } 2020 \\
N=27\end{array}$ & p-value \\
\hline Age (years), mean (SD) & $25.6(8.2)$ & $25.2(10.7)$ & $26.1(4.9)$ & 0.572 \\
\hline Male sex, $n(\%)$ & $29(55.8)$ & $17(60.7)$ & $12(44.4)$ & 0.016 \\
\hline \multicolumn{5}{|l|}{ Current workplace, n (\%) } \\
\hline Teaching hospital & $24(46.2)$ & $9(36.0)$ & $15(55.6)$ & 0.079 \\
\hline Government hospital center & $8(15.4)$ & $5(20.0)$ & $3(11.1)$ & \\
\hline General hospital & $6(11.5)$ & $3(12.0)$ & $3(11.1)$ & \\
\hline Community hospital & $4(7.7)$ & $\mathrm{I}(4.0)$ & $3(I I .1)$ & \\
\hline Private hospital & $5(9.6)$ & $3(12.0)$ & $2(7.4)$ & \\
\hline Other & $5(9.6)$ & $4(16.0)$ & I (3.7) & \\
\hline Previous jobs in health care system, $\mathrm{n}(\%)$ & $22(42.3)$ & $12(48.0)$ & $10(37)$ & 0.188 \\
\hline Advanced emergency medical technician & $12(23.1)$ & $5(20.0)$ & $7(25.9)$ & \\
\hline Emergency medical technician & I (I.9) & I (4.0) & 0 & \\
\hline Practical nurse & $2(3.8)$ & I (4.0) & I (3.7) & \\
\hline Other & $7(13.5)$ & $5(20.0)$ & $2(7.4)$ & \\
\hline Experience caring for patients receiving palliative care, $\mathrm{n}(\%)$ & $16(30.8)$ & $8(32.0)$ & $8(29.6)$ & 0.794 \\
\hline $\begin{array}{l}\text { Ability to recognize patients who are eligible for palliative } \\
\text { care, } n(\%)\end{array}$ & $\begin{array}{l}96 / 104 \\
(92.3)\end{array}$ & $45 / 50(90.0)$ & $5 \mathrm{I} / 54(94.4)$ & 0.477 \\
\hline
\end{tabular}

Abbreviation: SD, standard deviation. 
Table 2 Comparison of Decision-Making Skills Among Participants, by Class

\begin{tabular}{|c|c|c|c|c|c|c|c|c|c|}
\hline \multirow[t]{2}{*}{ Domain } & \multicolumn{3}{|c|}{ Patients without Malignancy } & \multicolumn{3}{|c|}{ Patients with Malignancy } & \multicolumn{3}{|c|}{ Overall Decision-Making } \\
\hline & $\begin{array}{c}\text { Class of } \\
\begin{array}{c}2019 \\
N=25 \\
n(\%)\end{array}\end{array}$ & $\begin{array}{c}\text { Class of } \\
\begin{array}{c}2020 \\
N=27\end{array} \\
n(\%)\end{array}$ & p-value & $\begin{array}{c}\text { Class of } \\
\begin{array}{c}2019 \\
N=25 \\
n(\%)\end{array}\end{array}$ & $\begin{array}{c}\text { Class of } \\
\begin{array}{c}2020 \\
N=27\end{array} \\
n(\%)\end{array}$ & p-value & $\begin{array}{c}\text { Class of } \\
\begin{array}{c}2019 \\
N=50 \\
n(\%)\end{array}\end{array}$ & $\begin{array}{c}\text { Class of } \\
\begin{array}{c}2020 \\
N=54 \\
n(\%)\end{array}\end{array}$ & p-value \\
\hline $\begin{array}{l}\text { I. Life-sustaining } \\
\text { treatment }\end{array}$ & $24(96.0)$ & $27(100.0)$ & $0.48 I$ & $23(92.0)$ & $27(100.0)$ & 0.226 & $47(94.0)$ & $54(100.0)$ & 0.108 \\
\hline $\begin{array}{l}\text { 2. Withholding or } \\
\text { withdrawing life- } \\
\text { sustaining treatment }\end{array}$ & $21(84.0)$ & $23(85.2)$ & 1.000 & $25(100.0)$ & $27(100.0)$ & - & $46(92.0)$ & $50(92.6)$ & 1.000 \\
\hline $\begin{array}{l}\text { 3. Advance care } \\
\text { planning, living will, } \\
\text { advance directive }\end{array}$ & $\mathrm{N} / \mathrm{A}$ & N/A & N/A & $24(96.0)$ & $26(96.3)$ & 1.000 & $24(96.0)$ & $26(96.3)$ & 1.000 \\
\hline 4. Self-autonomy & $25(100.0)$ & $27(100.0)$ & - & $24(96.0)$ & $27(100.0)$ & 0.481 & $49(98.0)$ & $54(100.0)$ & 0.481 \\
\hline $\begin{array}{l}\text { 5. Decision-making } \\
\text { capacity, surrogate } \\
\text { decision-maker }\end{array}$ & $25(100.0)$ & $27(100.0)$ & - & $25(100.0)$ & $27(100.0)$ & - & $50(100.0)$ & $54(100.0)$ & - \\
\hline $\begin{array}{l}\text { 6. Prehospital dyspnea } \\
\text { management }\end{array}$ & $21(84.0)$ & $25(92.6)$ & $0.4 \mathrm{II}$ & $\mathrm{N} / \mathrm{A}$ & $N / A$ & $\mathrm{~N} / \mathrm{A}$ & $21(84.0)$ & $25(92.6)$ & $0.4 \mathrm{II}$ \\
\hline 7. Communication skills & $25(100.0)$ & $26(96.3)$ & 1.000 & $25(100.0)$ & $27(100.0)$ & - & $50(100.0)$ & $53(98.1)$ & 1.000 \\
\hline
\end{tabular}

Table 3 Comparison of Overall Decision-Making According to Case (Malignancy and Non-Malignancy)

\begin{tabular}{|l|c|c|c|}
\hline Domain & Non-Malignancy N=52 n (\%) & Malignancy N=52 n (\%) & p-value \\
\hline I. Life-sustaining treatment & $51(98.1)$ & $50(96.2)$ & 1.000 \\
2. Withholding or withdrawing life-sustaining treatment & $44(84.6)$ & $52(100.0)$ & 0.006 \\
3. Advance care planning, living will, advance directive & N/A & $50(96.0)$ & - \\
4. Self-autonomy & $52(100.0)$ & $51(98.1)$ & 1.000 \\
5. Decision-making capacity, surrogate decision-maker & $52(100.0)$ & $52(100.0)$ & - \\
6. Prehospital dyspnea management & $46(88.5)$ & N/A & - \\
7. Communication skills & $51(98.1)$ & $52(100.0)$ & 1.000 \\
8. Recognition of patients eligible for palliative care & $44(84.6)$ & & 0.006 \\
\hline
\end{tabular}

previously. Despite the disease's prognosis, they insisted on us providing full ACLS care, including CPR.

Advance care planning and advanced directives have a crucial role in decision-making. According to previous studies, an advance care plan improves understanding among patients, families, and health care professionals. ${ }^{18,19}$ Health care personnel also find that advanced directives are an important tool in guiding their decision-making. ${ }^{3}$ Thailand National Health Act Section 12 permits anyone over 18 years of age to sign an advanced directive. ${ }^{21,22}$ However, the content of advance directives remains insufficient, outdated, or limited in real situations. ${ }^{4,23} 10$ out of 52 participants gave comments about this subject, including

Patients always had many descendants and sometimes also many caregivers, so it was difficult to determine who was the decision maker. This is an important reason for slowing the entire process.

The elderly in nursing homes are usually neglected by their families. We could not contact the real decision maker, so decisions were made by nursing home staff, which was not accepted by law and necessitated a full resuscitation to protect them. 
Apart from encouraging patients to have advance care plans and advanced directives, we suggest that patients have a legal document signed by a health care professional for emergency situations. More than two-thirds of participants make the same comment. As an example, "Living will is really important. We should encourage patients to get one before they become unable to make decisions in their lives." "We need legal documents signed by patients; it contributes to more appropriate, timely decisions."

Patients should have a wristband, any signs or documents showing that they do not want resuscitation. Real situations could be chaotic. Family and caregivers were confused and couldn't make immediate decisions.

A Physician Orders for Life-Sustaining Treatment (POLST) form is one example. This can serve as specific medical orders to guide EMS providers in an out-ofhospital setting ${ }^{24,25}$ and has been proven to effectively decrease the rate of unwanted resuscitation. ${ }^{5}$

Another major factor affecting emergency providers' decisions is medico-legal issues. ${ }^{3}$ According to Thailand National Institute of Emergency Medicine regulations, complicated medical procedures must be supervised by the medical director, including withholding or withdrawing life-sustaining treatment, making the decision not to transport patients to a hospital, and providing death notification to the family. ${ }^{26}$ Therefore, even though providers know the principles of palliative care, their actions are limited by law. ${ }^{3,11}$ Participants' experiences were shared: "I was called to an end-stage cancer patient with cardiac arrest, and his family insisted on full resuscitation.

We could not stop CPR until we arrived at the hospital. From my perspective, it prolongs death and wastes our resources.

This health regulation should be amended to permit EMS providers to take additional actions in out-ofhospital settings.

The EMS system also plays a role in prehospital decision-making. Several studies findings, as well as suggestions from 21 out of 52 participants in our study, indicate that EMS workers want action plans or clinical practice guidelines that enable them to provide appropriate care in these settings. ${ }^{5,11}$ Suggestions including:

Because we weren't sure about the disease's prognosis, we couldn't firmly advise family members. There should be some standard guidelines that we can follow or some useful information about common issues in prehospital palliative care.
"I propose that we have guidelines or protocols for paramedics that help us make the most appropriate decisions, both medically and legally." "A universal online database for accessing patient information and legal documents should be created."

The last factor we focused on in this study was the training curriculum for paramedic students. The current palliative care course is lecture-based and observational. We suggest modifying this teaching style. Simulationbased interventions, such as small group workshops and case-based scenarios, have been proven to increase understanding and confidence in palliative care skills. ${ }^{27}$ Lessons should include more formal education in palliative care strategies, ethical and legal aspects of advanced directives, symptom management in terminally ill patients, and communication skills. ${ }^{4,10}$ Participants' suggestions emphasized this need.

We did not know how to communicate effectively about the treatment goal. We frequently end up intubating and CPRing dying patients with advanced malignancy, because it prolongs their suffering.

I found the following two things to be extremely beneficial: 1) communication skills 2) knowledge of the disease, invasive procedures and their potential complications.

Paramedics and emergency personnel should be trained in palliative care, both intra and extracurricular. On-site practical training may be beneficial.

Emergency providers' decision-making is influenced by many factors. Our study focused mainly on the training curriculum, so our results might not be clinically relevant owing to various confounding factors. However, in the overall comparison, EMS personnel had better recognition and made more decisions to withhold or withdraw lifesustaining treatment in patients with malignancy than in those without malignancy. As patients without malignancy who are receiving palliative care have a slower course of disease and more varied disease trajectories, accurate prognosis is difficult. $^{28}$ Moreover, knowledge levels remain low among health care professionals regarding patients who are receiving palliative care. ${ }^{29}$

The result of this study showed that education and training program is not the only key factor to be initiated to improve the quality of EMS service for palliative care patients. The healthcare system, the EMS system, the national policy and patients' awareness are also crucial factors for driving change in EMS practice. Previous 
discussions demonstrated not only evidence but also rationale that would serve as a framework for future research in this field.

\section{Limitations}

This study has some limitations. To begin with, the study was carried out in our hospital, which is in an urban area and has its own palliative care training curriculum. Therefore, our results may not represent other cultural areas of the country. In addition, the scenarios and questions either put participants in a situation they might not have chosen or were driven by a range of on-scene factors. Furthermore, prehospital palliative care is still in the development stage in Thailand, and no related studies have been conducted in the country. Lastly, the number of participants were small that differences between the groups are unlikely to be very significant. Further studies with larger sample size in this field may be needed to examine more aspects of these systems.

\section{Conclusions}

Decision-making was not significantly different between emergency personnel who had and those who had not received training in palliative care. Overall, participants were able to recognize patients who are eligible to receive palliative care and could make the decision to withhold or withdraw life-sustaining treatment in advanced malignancy more often than in cases of non-malignancy.

\section{Acknowledgment}

We thank Analisa Avila, MPH, ELS, of Edanz (https:// www.edanz.com/ac) for editing a draft of this manuscript.

\section{Funding}

This research did not receive any specific grant from funding agencies in the public, commercial, or not-forprofit sectors.

\section{Disclosure}

The authors report no conflicts of interest in this work.

\section{References}

1. Lord B, Récoché K, O'Connor M, Yates P, Service M. Paramedics' perceptions of their role in palliative care: analysis of focus group transcripts. $J$ Palliat Care. 2012;28:36-40. doi:10.1177/ 082585971202800106

2. Quest TE, Marco CA, Derse AR. Hospice and palliative medicine: new subspecialty, new opportunities. Ann Emerg Med 2009;54:94-102. doi:10.1016/j.annemergmed.2008.11.019
3. Wiese $\mathrm{CH}$, Bartels UE, Zausig YA, Pfirstinger J, Graf BM, Hanekop GG. Prehospital emergency treatment of palliative care patients with cardiac arrest: a retrospective investigation. Support Care Cancer. 2010;18:1287-1292. doi:10.1007/s00520-009-0746-8

4. Murphy-Jones G, Timmons S. Paramedics' experiences of end-of-life care decision making with regard to nursing home residents: an exploration of influential issues and factors. Emerg Med $J$. 2016;33:722-726. doi:10.1136/emermed-2015-205405

5. Lamba S, Schmidt TA, Chan GK, Todd KH, Grudzen CR, Weissman DE. Integrating palliative care in the out-of-hospital setting: four things to jump-start an EMS-palliative care initiative. Prehosp Emerg Care. 2013;17:511-520. doi:10.3109/10903127.2013.811566

6. National Consensus Project for Quality Palliative Care. Clinical Practice Guidelines for Quality Palliative Care. 4th ed. Richmond, VA: National Coalition for Hospice and Palliative Care; 2018:1-10, 13-9, 52-7. Available from: https://www.nationalcoalitionhpc.org/ ncp. Accessed September 24, 2021.

7. Carron PN, Dami F, Diawara F, Hurst S, Hugli O. Palliative care and prehospital emergency medicine: analysis of a case series. Medicine. 2014;93:e128. doi:10.1097/MD.0000000000000128

8. Lord B, Andrew E, Henderson A, Anderson DJ, Smith K, Bernard S. Palliative care in paramedic practice: a retrospective cohort study. Palliat Med. 2019;33:445-451. doi:10.1177/0269216319828278

9. Gisondi MA, Dave WL, Yen M, et al. Adaptation of EPEC-EM ${ }^{\mathrm{TM}}$ curriculum in a residency with asynchronous learning. West J Emerg Med. 2010;11:491-498.

10. Shaw J, Fothergill R, Murphy-Jones G. Does current pre-hospital care for patients at the end of their life reflect best practice guidance? Emerg Med J. 2015;32:e12-e18. doi:10.1136/emermed-2015-204980.5

11. Taghavi M, Simon A, Kappus S, et al. Paramedics experiences and expectations concerning advance directives: a prospective, questionnaire-based, bi-centre study. Palliat Med. 2012;26:90-91. doi:10.1177/0269216311419885

12. Gisondi MA. A case for education in palliative and end-of-life care in emergency medicine. Soc Acad Emerg Med. 2009;16:178-183.

13. Shannon SE, Long-Sutehall T, Coombs M. Conversations in end-oflife care: communication tools for critical care practitioners. Nurs Crit Care. 2011;16:124-130. doi:10.1111/j.1478-5153.2011.00456.x

14. Altman DG. Practical Statistics for Medical Research. London: Chapman and Hall; 1991.

15. Wiese CH, Lassen CL, Bartels UE, et al. International recommendations for outpatient palliative care and prehospital palliative emergencies - a prospective questionnaire-based investigation. $B M C$ Palliat Care. 2013;12:10. doi:10.1186/1472-684X-12-10

16. Adelson K, Paris J, Horton JR, et al. Standardized criteria for palliative care consultation on a solid tumor oncology service reduces downstream health care use. J Oncol Pract. 2017;13:e431-e440. doi:10.1200/JOP.2016.016808

17. Finlay E, Newport K, Sivendran S, Kilpatrick L, Owens M, Buss MK. Models of outpatient palliative care clinics for patients with cancer. J Oncol Pract. 2019;15:187-193. doi:10.1200/ JOP.18.00634

18. Hallman K, Newton S. Outpatient palliative care: a case study illustrating clinic support offered to patients receiving cancer treatment. Clin J Oncol Nurs. 2019;23:203-208.

19. Waldrop DP, McGinley JM, Dailey MW, Clemency B. Decisionmaking in the moments before death: challenges in prehospital care. Prehosp Emerg Care. 2019;23:356-363. doi:10.1080/10903127.20 18.1518504

20. Seow H, O’Leary E, Perez R, Tanuseputro P. Access to palliative care by disease trajectory: a population-based cohort of Ontario decedents. BMJ Open. 2018;8:e21147. doi:10.1136/bmjopen-2017-021147

21. Government RT. Thai National Health Act 2007. Bangkok: Royal Thai Government Gazette; 2007:2-6. Available from: https://www. dms.go.th/backend//Content/Content_File/Information_Center/ Attach/25621124013609AM_17.pdf. Accessed September 24, 2021. 
22. Thai National Health Commission Office. Guidelines for Public Health Facilities, Public Health Practitioners and Staff of Public Health Facilities in Accordance with Ministerial Regulations for the Implementation of the Advanced Care Plan. Bangkok: Royal Thai Government Gazette; 2010:1-22. Available from: https:// www.thailivingwill.in.th/sites/default/files/021_livingwill.pdf. Accessed September 24, 2021.

23. Mack DS, Dosa D. Improving advanced care planning through Physician Orders for Life-Sustaining Treatment (POLST) expansion across the United States: lessons learned from state-based developments. Am $J$ Hosp Palliat Care. 2020;37:19-26. doi:10.1177/1049909119851511

24. Zive D, Newgard CD, Lin A, Caughey AB, Malveau S, Eckstrom E. Injured older adults transported by emergency medical services: one year outcomes by POLST status. Prehosp Emerg Care. 2020;24:257-264. doi:10.1080/10903127.2019.1615154

25. Zive DM, Jimenez VM, Fromme EK, Tolle SW. Changes over time in the Oregon physician orders for life-sustaining treatment registry: a study of two decedent cohorts. J Palliat Med. 2019;22:500-507. doi:10.1089/jpm.2018.0446
26. National Institute of Emergency Medicine. Authority, Duty, Scope of Responsibility, and Limitations in the Performance of Medical Assistant According to the Order of Medical Director. Bangkok: Royal Thai Government Gazette; 2013:1-13. Available from: http://register.niems. go.th/niEMS_EDU/Upload/File/201802221806354517_ 6eIRcw3icUmlZY1I.pdf. Accessed September 24, 2021.

27. Goldonowicz JM, Runyon MS, Bullard MJ. Palliative care in the emergency department: an educational investigation and intervention. BMC Palliat Care. 2018;17:43. doi:10.1186/s12904-018-0293-5

28. Bostwick D, Wolf S, Samsa G, et al. Comparing the palliative care needs of those with cancer to those with common non-cancer serious illness. J Pain Symptom Manage. 2017;53:1079-1084. doi:10.1016/j. jpainsymman.2017.02.014

29. Kim S, Lee K, Kim S. Knowledge, attitude, confidence, and educational needs of palliative care in nurses caring for non-cancer patients: a cross-sectional, descriptive study. BMC Palliat Care. 2020;19:105. doi:10.1186/s12904-020-00581-6
Advances in Medical Education and Practice

\section{Publish your work in this journal}

Advances in Medical Education and Practice is an international, peerreviewed, open access journal that aims to present and publish research on Medical Education covering medical, dental, nursing and allied health care professional education. The journal covers undergraduate education, postgraduate training and continuing medical education

\section{Dovepress}

including emerging trends and innovative models linking education, research, and health care services. The manuscript management system is completely online and includes a very quick and fair peer-review system. Visit http://www.dovepress.com/testimonials.php to read real quotes from published authors. 